\title{
Corrigendum
}

\section{Alzheimer disease $\beta$-amyloid activity mimics cholesterol oxidase}

Luigi Puglielli, Avi L. Friedlich, Kenneth D.R. Setchell, Seiichi Nagano, Carlos Opazo, Robert A. Cherny, Kevin J. Barnham, John D. Wade, Simon Melov, Dora M. Kovacs, and Ashley I. Bush

Original citation: J. Clin. Invest. 115:2556-2563 (2005). doi:10.1172/JCI23610.

Citation for this corrigendum: J. Clin. Invest. 116:2828 (2006). doi:10.1172/JCI23610C1.

The Acknowledgments section was incomplete. The corrected Acknowledgments section appears below.

This work was supported by grants from the National Institute on Aging (AG12686 to A.I. Bush and AG18679 to S. Melov), the Alzheimer's Association (to L. Puglielli and A.I. Bush), the National Health and Medical Research Council (to A.I. Bush), the Institute for the Study of Aging (to S. Melov), and the National Institute of Neurological Disorders and Stroke (to D.M. Kovacs and postdoctoral fellowship grant F32NS10874 to A.L. Friedlich). This work was also supported by a grant from the American Health Assistance Foundation. Tissue was supplied by the Harvard Brain Tissue Resource Center (supported by grant R24MH68855 from the National Institute of Mental Health). We thank Tobias Hartmann for helpful suggestions.

The authors regret this error.

\section{Corrigendum}

\section{Bacterial neuraminidase facilitates mucosal infection by participating in biofilm production}

Grace Soong, Amanda Muir, Marisa I. Gomez, Jonathan Waks, Bharat Reddy, Paul Planet, Pradeep K. Singh, Yukihiro Kaneko, Matthew C. Wolfgang, Yu-Shan Hsiao, Liang Tong, and Alice Prince

Original citation: J. Clin. Invest. 116:2297-2305 (2006). doi:10.1172/JCI27920.

Citation for this corrigendum: J. Clin. Invest. 116:2828 (2006). doi:10.1172/JCI27920C1.

In the original author list, Yukihiro Kaneko's name appeared incorrectly. The corrected author list appears above.

The authors regret this error.

\section{Corrigendum}

\section{Human $\mathrm{CD}^{+} \mathrm{CD}^{2} 5^{\mathrm{hi}} \mathrm{Foxp}^{+}$regulatory $\mathrm{T}$ cells are derived by rapid turnover of memory populations in vivo}

Milica Vukmanovic-Stejic, Yan Zhang, Joanne E. Cook, Jean M. Fletcher, Arthur McQuaid, Joanne E. Masters, Malcolm H.A. Rustin, Leonie S. Taams, Peter C.L. Beverley, Derek C. Macallan, and Arne N. Akbar

Original citation: J. Clin. Invest. 116:2423-2433 (2006). doi:10.1172/JCI28941.

Citation for this corrigendum: J. Clin. Invest. 116:2828 (2006). doi:10.1172/JCI28941C1.

During the preparation of this manuscript for publication, errors were introduced in the labels for Figure 4C. The corrected figure appears below.

The authors regret this error. 